Max-Planck-Institut für demografische Forschung

Max Planck Institute for Demographic Research

Konrad-Zuse-Strasse 1 - D-18057 Rostock · GERMANY

Tel +49 (0) 3812081 - 0; Fax +49 (0) 3812081 - 202;

http://www.demogr.mpg.de

MPIDR WORKING PAPER WP 2005-009

APRIL 2005

\title{
Why does Sweden have such high \\ fertility?
}

Jan M. Hoem (hoem@demogr.mpg.de)

(C) Copyright is held by the author.

Working papers of the Max Planck Institute for Demographic Research receive only limited review. Views or opinions expressed in working papers are attributable to the authors and do not necessarily reflect those of the Institute. 


\title{
Why does Sweden have such high fertility?
}

\author{
A presentation to the annual meeting of the \\ Deutsche Gesellschaft für Demographie, Potsdam, 16 March $2005^{1}$ \\ by Jan M. Hoem, \\ Max Planck Institute for Demographic Research, Rostock, Germany
}

\begin{abstract} During the 1980s and 1990s, the annual Total Fertility Rate (TFR) for Sweden undulated considwell above the level in West Germany. (In 2004 the Swedish TFR reached 1.76 on an upward trend.) The Swedish completed Cohort Fertility Rate (CFR) was rather constant at 2 for the cohorts that produced children in the same period; for France it stayed around 2.1 while the West-German CFR was lower and declined regularly to around 1.6. In this presentation, I describe the background for these developments and explain the unique Swedish undulations. public family policies in the country. They reflect the great generosity, high flexibility, and universalistic approach of the whole system, where family policies are coordinated with educational policies and labor-market policies in an effort to promote the status of women and achieve equity for all residents. The state has been engaged in the development of high-quality all-day childcare arrangements available to all children, and has conducted campaigns to influence public attitudes toward a woman-friendly political culture. Reforms have been motivated by gender-equality considerations and by a drive to induce women to participate in the labor force and to induce men into parenting and childrearing. Legal rules are individualistic, as highlighted by the abolishment of the public widow's pension and by a tax system where income tax is levied from the individual and not from the married couple or the household, as in Germany. Welfare-state benefits are directed similarly to the individual, not to the family. Policies can be said to focus on the equal right of working women to have children rather than of the right of mothers to have a job. There is no inclination in the Swedish system to encourage a mother to stay home and take care of her children; if anything there has been a move toward securing both-parent participation in childrearing.

Content

1. The bare facts

2. The effect of education

3. Swedish family policies and their German counterparts

4. The woman-friendly Swedish political culture

5. Reflections

Acknowledgements

References

Figures

Page
2
3
4
6
7
8
8
10
\end{abstract}

By current European standards, Sweden has had a relatively high fertility in recent decades. erably around a level just under 1.8, which is a bit lower than the corresponding level in France and

Part of the explanation of the trend and level in Swedish fertility is the extensive battery of

\footnotetext{
${ }^{1}$ The subject title was pre-set by the organizers of the conference, whom I thank for inviting me. The original talk was based on a set of transparencies whose content is incorporated here. I have tried to retain the spirit of an oral presentation rather than to formulate a normal full-text account. The main concession to the style of a usual journal article is that I have now provided references to the existing literature. Readers interested in more documentation should consult the references. The present text is scheduled to appear in a volume of contributions to the Potsdam conference.
} 


\section{The bare facts}

As is well known, Sweden is among the countries that have had a rather high fertility in recent years by European standards, particularly as compared to Germany. Figure 1 shows how this is reflected in a plot of the TFR series since 1980. The diagram also contains the TFR curve for France because another presentation to the Potsdam meeting focused on France (Chenet, 2005), and the curve for Finland for a reason that we shall explain presently. Two features of the diagram immediately strikes the eye, namely that (i) the curve for Germany lies well below any of the others, and (ii) the curve for Sweden has a strong wave form with a peak in 1990 (with TFR=2.13) and a low-point in 1998 and 1999 (TFR=1.5). The other curves are much more stable; in particular there is no similarly prominent wave-form in the curve for Finland, nor is there for the other Nordic countries (not displayed here, but see, e.g., Andersson 2005, Figure 1). We shall provide some insight into the unique roller-coaster development in Swedish fertility in a minute. Meanwhile, let us note that the much more stable curve for all of Germany in reality covers up some dramatic trends in East Germany brought about by the fall of communism and the subsequent re-unification of Germany; see Figure 2. Important political and economic events can have a strong impact on fertility.

\section{$<$ Figures 1 and 2 about here>}

It is important to note that in many cases, such impacts work primarily through tempo effects (a re-orientation of the start of childbearing and of the speed of subsequent childbearing); the effect on the end result (ultimate fertility) may be much smaller. Even the striking waves in Swedish period fertility are smoothed out in a plot of the corresponding mean number of children ever born to the birth cohorts of women that contributed to the TFR curve in Figure 1. The cohortfertility curve for Sweden in Figure 3 is remarkably stable, and it lies well above the curves for the two parts of Germany, both of which drop considerably over the twenty-five cohorts in the diagram. For the cohort born in 1965, which is now forty years old and has essentially completed its childbearing, the mean ultimate number of children was 1.98 in Sweden and only a very low 1.57 and 1.48 in East and West Germany, respectively.

\section{<Figure 3 about here>}

The increase in the Swedish TFR in the 1980s was most likely brought about by two developments that worked together (Hoem and Hoem, 1996). First, the economic situation was quite good and improving in that period, so Swedish families could progressively more easily afford a child (or more children). Second, changes in Swedish family policies strongly encouraged closer spacing of children. Here is how:

In public family-insurance systems where benefits are related to earnings, as in Sweden, parents are induced to time their births so as to optimize their stream of total income and benefits. If benefits must be earned by periods of recorded earnings, there is an inducement to postpone the beginning of childbearing until rights to suitable benefits have been established. There is also a corresponding inducement to space subsequent children in a manner that avoids penalizing the recipient in consequence of a low earned income during the interval between births. In Sweden, the benefit level connected to child number two, three, and so on is the same as after the preceding child if the previous benefit level was above what the parent gains during the current birth interval, provided that the previous interval did not exceed a prescribed number of months. ${ }^{2}$ After some precursors in legal practice, this rule was made statutory in 1980 and the "eligibility interval" was then set to 24 months. In 1986, it was extended to (more attainable) thirty months. The most convincing demonstration of a corresponding lasting speed-up effect in childbearing has been given by Andersson (1999, 2004).

\footnotetext{
${ }^{2}$ By analogy to sales tricks used by mail-order firms, particularly in books sales, we have termed this feature a "speed premium on the next child" (Hoem 1990).
} 
In the 1990s, the economy turned sour and family incomes fell. Benefits fell correspondingly, and families must have felt that they could much less easily "afford" (further) children. In response to rising unemployment and encouraged by public re-training policies, many women and men moved into education, or stayed on if they were already enrolled; during enrollment, women get fewer children than otherwise. The annual TFR fell in step with these developments. We got the trough in the TFR curve shown in Figure 1 because incomes and employment rose again after the bad times in the 1990s, and the TFR followed suit. Since the corresponding CFR remained quite stable (Figure 3), the mechanism that produced the waves in the TFR must have been some shiftaround of the age at childbearing and tempo of childbearing.

Public policies in other Nordic countries had different details. In Finland they introduced a benefit called the home-care allowance ${ }^{3}$ in 1985 and had the program fully developed when the economic crisis hit in the early 1990s. The benefit consisted in a monthly support payment to parents who did not make use of public child-care. It means that women who became unemployed and stayed at home with their child (or children), got a generous public subsidy which helped them tide over the difficult times until they could go back to work. ${ }^{4}$ Evidently, such a policy evened out family income streams and correspondingly smoothed out fertility waves. It has not been possible politically to maintain a home-care allowance in Sweden, and this country's regulations make the fertility level vary pro-cyclically. By contrast, the Finnish system has succeeded in working against business cycles (Vikat, 2004). Note that labor-force participation is very high among Swedish and Finnish women, and that public child care is readily available, so it is not very problematic to get a child-care space when a new job opening is found after a spell of unemployment.

\section{The effect of education}

Much attention has been given recently to the discovery that highly educated German women have much higher childlessness than other women. As we see in Figure 4, the more highly educated $^{5}$ do appear to have fewer children on average. ${ }^{6}$ Two observations are in order:

(i) Highly educated French and Swedish women have a much higher mean ultimate number of children on average than their West German counterparts.

(ii) The two curves for Sweden are much closer together than the two curves for each of the other countries. Evidently, educational level is much less important for ultimate fertility in Sweden than in France and West Germany. ${ }^{7}$

Our interpretation is that Swedish public policies make it much easier to combine childbearing and (even career-oriented) labor-market participation than in the two other countries we have in focus. That combination seems particularly difficult in Germany.

\section{$<$ Figure 4 about here $>$}

\footnotetext{
${ }^{3}$ See Ilmakunnas (1997), Vikat (2004), Neyer (2005).

${ }^{4}$ When the crisis hit, the home-care allowance was paid on top of unemployment benefits. Since then, the home-care allowance has been reduced and ceilings have been introduced on the total benefits that can be drawn in parallel.

${ }^{5}$ In Figure 4, there are two curves for each country, namely one for women with only basic education and another one (marked "tertiary ed") for women who have completed at least a certificate or academic degree after their secondary education, i.e., after the "Abitur" in Germany, the "lycee" in France, and the "gymnasium" in Sweden.

${ }^{6}$ We have data available for single-year birth cohorts in France and Sweden, but only for five-year cohorts in Germany. Therefore, the curves for (West) Germany in Figure 4 consist of widely separated points, while for France and Sweden we can plot connected curves.

${ }^{7}$ In a study of third-birth rates, Corman $(2001,2004)$ suggests that the determining mechanism may be the much greater availability of part-time work in Sweden than in France.
} 


\section{Swedish family policies and their German counterparts}

Overviews over Swedish family policies have been given by Hoem and Hoem (1996). ${ }^{8}$ In a

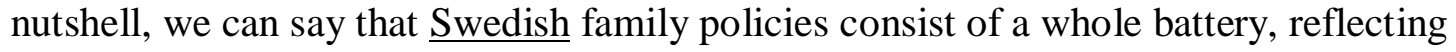

- great generosity,

- high flexibility,

- a universalistic approach, (which means that the same provisions are used all over Sweden and that rules and benefits are independent of social status, of marital status, and so on),

- co-ordination with flexible educational policies ${ }^{9}$ and flexible labor-market policies, and

- a general promotion of women.

An easy way of seeing the contrast to the policies in (the now united) Germany is to "correct" the list items as follows: ${ }^{10}$

German family policies reflect

- great generosity,

- high some flexibility,

- a universalistic familistic approach (Esping-Andersen 1999); [while the same provisions are used all over Sweden and rules and benefits are independent of social status, of marital status, and so on; benefits are paid to individuals] in Germany rules depend on family status and benefits are directed to families, not individuals,

- eo-ordination with flexible educational policies and flexible labor market policies, and

- a general promotion of women.

There is considerable generosity in the German system as well, not least in the way tax is levied on family units, with special tax rebates for children and for marriages. Public health care is also directed toward the married couple and their children. These features have long been completely absent in the Swedish system. Coordination between family policies and policies in other arenas are much less consistent in Germany than in Sweden. And in Germany I have noticed little of the consistent activities toward gender equality and support for women's self-dependent status (Frauenförderung) that is such a prominent feature of life in Sweden. Instead the accent is on supporting and protecting the married family, and on largely leaving the provision of care and welfare to families (an application of the principle of subsidiarity).

Here are some features of the current $\underline{\text { Swedish battery of family policies }}{ }^{11}$ :

Parental leave, now with a benefit at $80 \%$ of earned income, ${ }^{12}$ for 13 months, ${ }^{13}$ plus 3 more months at a relatively low benefit not related to income;

${ }^{8}$ For an embedding of Sweden in the Western-European community, see Hantrais (2000, 2004), Björklund (2005), Rønsen and Sundström (2002), and Neyer (2003, 2005).

${ }^{9}$ Hoem, Neyer, and Andersson (2005) argue that a flexible educational system works toward increasing fertility. For more reflections on the generosity and flexibility of the Swedish system, see Hoem, Prskawetz, and Neyer (2001, Appendix C).

${ }^{10}$ For a more extensive account of the German situation, see Kreyenfeld and Konietzka (2004).

${ }^{11}$ We skip their long prehistory, for which we refer to the references given at the start of the current section. The details of the regulations change all the time. What follows it the current state of affairs as of May 2004 (which currently is the latest time for which the regulations are easily available on the Internet).

12 There is a high upper limit for the total amount of benefit.

${ }^{13}$ Two of these months are reserved for the father and two more for the mother; the rest can be taken by either parent. 
- great flexibility through part-time use and varying take-out over time;

- unconditional right to part-time work;

- right to return to work.

Speed premium when there are no more than 30 months between children. ${ }^{14}$

"Daddy days": Ten benefit days are awarded to the father in connection with each childbirth.

Time for sick-child care, now up to 120 paid days per year per child (covers sickness of care personnel also).

Cash child-benefit, currently at about $900 €$ per year per child. Also house-rent support in case of need.

All-day daycare and all-day schools: high-quality low-cost public coverage that fully meets demand for children in all age groups, also for school-children.

We compare this list as follows to highlight the differences with German policies:

Parental leave, now with an income-dependent benefit at up to a maximum of $300 €$ per month, up to 24 months, ${ }^{15}$ with twelve more months without any benefit payment [against Sweden's much higher $80 \%$ income replacement allowance, paid for 13 months, plus 3 more months at a low benefit not related to income];

- great flexibility through part-time use and varying take-out over time (recently introduced in Germany also);

- right to part-time work;

- right to return to work.

Speed premium when there are no more than 30 months between children.

Time for sick-child care, now 120 10-20 paid days per year per child (covers sickness of eare persennel also).

Cash child-benefit, currently income-dependent and at about $900 € 1850-2150 €$ per year per child. Also house-rent support in case of need.

"Daddy days": Ten benefit days are awarded to the father in connection with childbirth.

Daycare: Very limited in Germany by comparison to Sweden. ${ }^{16}$ Daycare and schools in Germany are typically open only before lunch, a feature which is particularly detrimental to a mother's participation in the labor force. [In Sweden: high quality low-cost public coverage that fully meets demand for children in all age groups, for also school-children.]

As we have noted already, the German system also has extensive tax rebates for families, and it has family-related health-insurance coverage.

In both countries (in contrast to, say, in the United States),

- there is careful public supervision of childcare arrangements, also of co-operatives, nonprofit organizations, and private arrangements ("day-care mothers" and the like) $)^{17}$,

\footnotetext{
${ }^{14}$ We described this feature in Section 1.

${ }^{15}$ One can get the amount increased to $460 €$ by restricting the parental-leave period to one year.

${ }^{16}$ There is complete public coverage of part-time care in Germany for children of Kindergarten age. Very limited fulltime care, very limited care for infants and school-age children (outside of school) in the western parts of Germany (alte Bundesländer). High coverage in the east (neue Bundesländer).

17 "Day-care mothers" provide childcare in their own homes. Private arrangements seem to be less frequent in Germany.
} 
- investments are made in buildings and equipment for day-care and schooling (but much more extensively in Sweden);

- education of qualified personnel is a public service; and

- great store is put in the symbol value of public statements.

The content and tone of those public statements are noticeably different in the two countries, however. There are not only factual policy differences between Germany and Sweden; those differences also reflect differences in mentality and in policy goals. In Sweden (where public engagement in family policies seems much the stronger) there is a determined egalitarian drive, and publicfinanced campaigns are conducted to influence public opinion further toward gender equality. There is also a broad political consensus about the general goals in Sweden. By contrast, there are marked political differences among parties and interest groups regarding family policies in Germany ${ }^{18}$ and with few exceptions the public statements that I have noticed largely seem to refer to impossibilities induced by the federal constitution. In Sweden, there have been continual efforts to build out the system since the 1960s, and during the difficult financial period in the 1990s, the struggle was to maintain (not to reduce or abolish) existing standards. In Germany, the concern seems mostly to be directed toward retaining the status quo rather than to introduce any major innovation; in fact the struggle is reminiscent of what happened in Sweden some forty years ago, particularly as regards the struggle for a change in mentality.

\section{The woman-friendly Swedish political culture}

It is important to realize that the differences in fertility impacts are not solely the product of single items in the battery of family policies, or even groups of such items. The Swedish situation is characterized by a political culture essentially different from what one experiences in Germany, particularly in West Germany. Here are some features that justify an assessment of the Swedish political culture as much more woman-friendly than the German culture:

- As we have mentioned already, the unit toward which policies are directed is the individual in Sweden and the married couple in Germany. This is highlighted by their contrasting systems of income tax and social security. In Sweden, each individual is taxed for his or her income and has his or her own social-security coverage. In Germany the family is taxed for the joint income of its members and the social-security unit is again the married couple.

- Sweden has a forceful drive toward gender equality in every area of private and public life, including education and the labor market. It is hard to see that Germany is anywhere near as interested in such aspects. In Sweden, considerations concerning gender-equality and social justice have guided reforms in family (and other) policies. The reforms have not had an explicit pro-natalist motivation beyond a desire to enable everyone to have the children they want.

- Sweden has a decidedly more flexible educational system (for adults). Women (and men) may return to take more education after a break, perhaps after the arrival of a child. This means that the arrival of a child does not have to imply the end of educational attainment. In a less flexible system, young women may be discouraged from childbearing because they fear that once their educational enrollment is interrupted it may be impossible to continue their studies.

- The Swedish system has a clear child-oriented perspective. It is child-friendly by being woman-friendly. It emphasizes the "equal right of working women to also have children" instead of "the right of mothers to have employment" (a formulation due to Alva Myrdal). There is nothing

\footnotetext{
${ }^{18}$ One example it the attitude to full-time schooling, a practice that probably greatly influences a woman's possibility of combining motherhood and job. The federal government has reserved large sums of money to expand full-time schooling. However, in Germany the Bundesländer are responsible for organizing public education. In the end, some conservative Bundesländer did not use the money they were offered because they had political objections to full-time schooling.
} 
about the system that works toward enabling mothers to stay home and take care of their children; quite on the contrary, the whole system encourages women to get a job and keep it ("arbetslinjen").

- The Swedish system puts great store on regarding daycare as a pedagogical opportunity and the whole system as a tool toward promoting equal opportunities for all children, not as a means of guarding children while their mothers are at work. Attempts at restricting daycare to save money have met with strong resistance in the population. (Such attempts have consisted for instance in wanting couples to take their older child or children out of daycare temporarily when a family member stays at home with a new child during parental leave. This has been seen as an infringement on the children's pedagogical rights.)

- Swedish policies encourage both-parent participation in childrearing. For instance, each parent must take two of the thirteen paid months of parental leave, as we have noted already. The strongest criticism now heard in Sweden is that men do not participate enough on the home front.

\section{Reflections}

As is evident from the account above, the family politics of Germany and Sweden reflect quite different priorities. In Sweden, the emphasis is on gender equality, on inducing women (and of course men) to go into the labor force and staying there, on using flexible educational and labor systems to promote these goals (and, as a consequence, improving the compatibility of parenthood and labor-force participation), and on providing children with professional pedagogical opportunities that families find attractive, also when the children are very young. In Germany, the emphasis is on promoting the classical single-earner family and encouraging mothers to stay at home. Germany suffers some consequences of these priorities. At this time and day, better-educated German women evidently prefer to limit their childbearing or to go childless rather than to endanger their job; other women may catch the same trend. If they want to prevent German fertility from declining further and perhaps to get it moving on an upward track, German opinion leaders may have to abandon their current legalistic argumentation about the protection of the family incorporated in the federal constitution. Improving the German economy is likely to help, but short of a miracle, changing the general priorities of family politics seems needed if Germany wants more children. (Perhaps a reinterpretation of the constitution may be enough, even though it seems politically difficult at the moment.) Independently of fertility considerations, inducing more women into paid employment and promoting gender equality in the labor market may also be an important item in a response to a shrinking labor force as the population ages. In this process, some inspiration may be found in the experience of the Nordic countries.

Not that Swedish politics does not also have their holy cows. As we mentioned above, the great undulations in Swedish fertility are largely self-induced by the tight links between parenthood benefits and preceding income from a woman's own labor-force participation. Such waves in the number of births have repercussions as day-care facilities and later the whole educational system have to expand and contract in line with the varying sizes of young cohorts. The Finnish solution with a home-care allowance has turned out to be politically infeasible in Sweden. A modest introduction a decade ago was fought and quickly rejected, largely on the argument that it would create a trap that would keep women in the kitchen and out of the labor force. ${ }^{19}$ This argument does not seem to have had the same political appeal in Finland, and the question is what balance a society wants to strike when it weighs female empowerment against stability in the sizes of birth cohorts in a situation with universal high-quality childcare coverage and relatively advanced gender equality.

\footnotetext{
${ }^{19}$ Findings by Rønsen and Sundström (2002) suggest that there may be a grain of truth in such an argument.
} 


\section{Acknowledgements}

The author is grateful to Gerda Neyer, Michaela Kreyenfeld, and Gunnar Andersson for very helpful cooperation. Anders Björklund kindly made available the data from which I have produced Figure 4. Dorothea Rieck provided competent research assistance.

\section{References}

Andersson, Gunnar (1999). Childbearing trends in Sweden 1961-1997. European Journal of Population 15, 1-24.

Andersson, Gunnar (2004). Childbearing developments in Denmark, Norway, and Sweden from the 1970s to the 1990s: a comparison. Demographic Research Special Collection No. 3 (7), 155176.

Andersson, Gunnar (2005). A study on policies and practices in selected countries that encourage childbirth: the case of Sweden. Contribution to the Consultancy Study on Population Related Matters - A Study on Policies and Practices in Selected Countries that Encourage Childbirth, for the Government of Hong Kong Special Administrative Region. Max Planck Institute for Demographic Research Working Paper 2005-5. Download from http://www.demogr.mpg.de/Papers/Working/wp-2005-005.pdf

Björklund, Anders (2005). Does family policy affect fertility. Journal of Population Economics, forthcoming.

Chenet, Jean-Claude (2005). Why the French fertility is preserved from collapse. Contribution to the annual meeting of the Deutsche Gesellschaft für Demographie, Potsdam, 16 March 2005.

Corman, Diana (2001). Success at Work and in Family Life: Studies in Selected Western Fertility and Family Dynamics. Stockholm University Demography Unit.

Corman, Diana (2004). Deltid främjar ett tredje barn. Välfärd (Statistics Sweden) 2004/4, pp. 6-8.

Esping-Andersen, Gösta (1999). Social Foundations of Postindustrial Economies. Oxford University Press.

Hantrais, Linda (Ed., 2000). Gendered Policies in Europe. Reconciling Employment and Family Life. Macmillan, London.

Hantrais, Linda (2004). Family Policy Matters: Responding to Family Change in Europe. Policy Press, Bristol.

Hoem, Britta and Jan M. Hoem (1996). Sweden's family policies and roller-coaster fertility. Journal of Population Problems 52 (3-4); 1-22.

Hoem, Jan M. (1990). Social policy and recent fertility change in Sweden. Population and Development Review 16 (4), 735-748.

Hoem, Jan M., Alexia Prskawetz, and Gerda Neyer (2001). Autonomy or conservative adjustment? The effect of public policies and educational attainment on third births in Austria. Max Planck Institute for Demographic Research, Working Paper 2001-16. Download from http://www.demogr.mpg.de/Papers/Working/wp-2001-016.pdf.

Hoem, Jan M., Gerda Neyer, and Gunnar Andersson (2005). Childlessness and educational attainment among Swedish women born in 1955-59. Forthcoming as a Working Paper from the Max Planck Institute of Demographic Research, Rostock.

Ilmakunnas, Seija (1997). Public policy and childcare choice. Pp. 178-193 in ed. by Inga Persson and Christina Jonung, (Eds.), Economics of the Family and Family Policies. Routledge, London. 
Kreyenfeld, Michaela and Dirk Konietzka (2004). Familienpolitik und Geburtenentwicklung in Deutschland. Pp. 64-87 in Milbradt, Georg and Johannes Meier (Eds.), Die demographische Herausforderung - Sachsens Zukunft gestalten. Verlag Bertelsmann Stiftung.

Neyer, Gerda (2003). Family policies and low fertility in Western Europe. Journal of Population and Social Security (Population) 1: Suppl., 46-93. For an extended version with references, see Max Planck Institute for Demographic Research, Working Paper 2003-21. Download from http://www.demogr.mpg.de/Papers/Working/wp-2003-021.pdf.

Neyer, Gerda (2005).Family policies in Western Europe. Fertility policies at the intersection of gender policies, employment policies and care policies. Österreichische Zeitschrift für Politikwissenschaft 2005 (1), forthcoming.

Rønsen, Marit and Marianne Sundström (2002). Family policy and after-birth employment among new mothers - a comparison of Finland, Norway and Sweden. European Journal of Population 18; 121-152.

Vikat, Andres (2004). Women's labor force attachment and childbearing in Finland. Demographic Research Special Collection No. 3 (8), 175-211. 


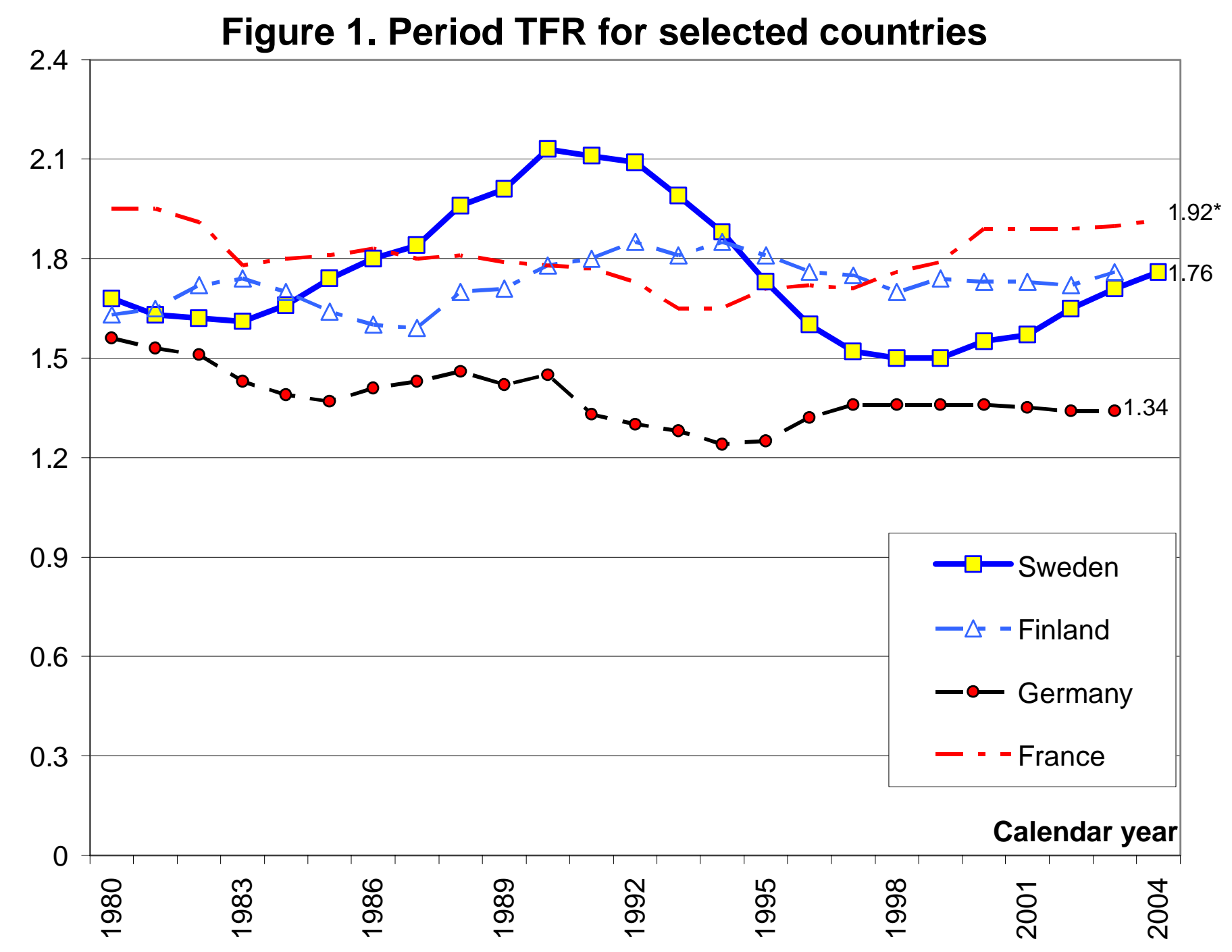




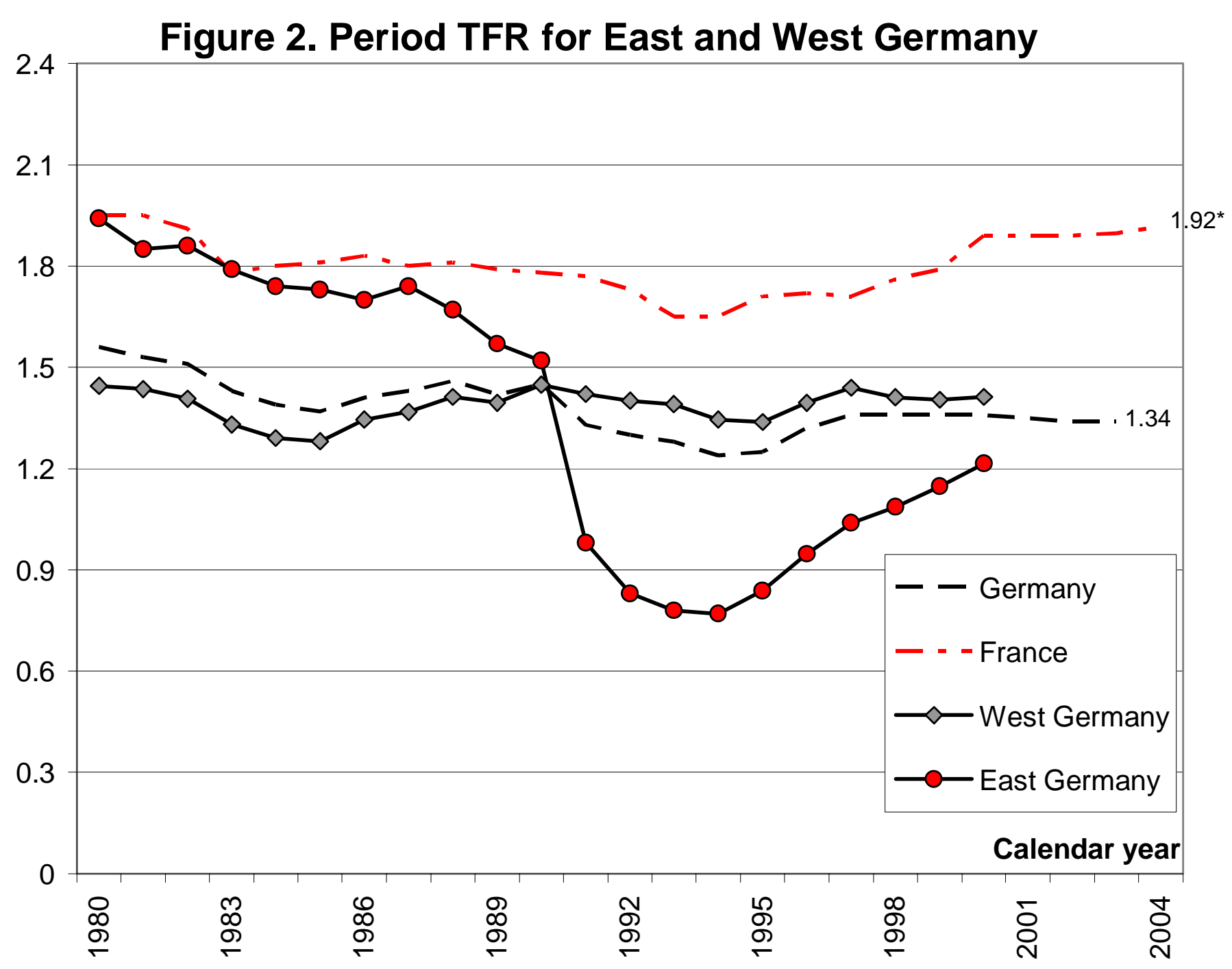




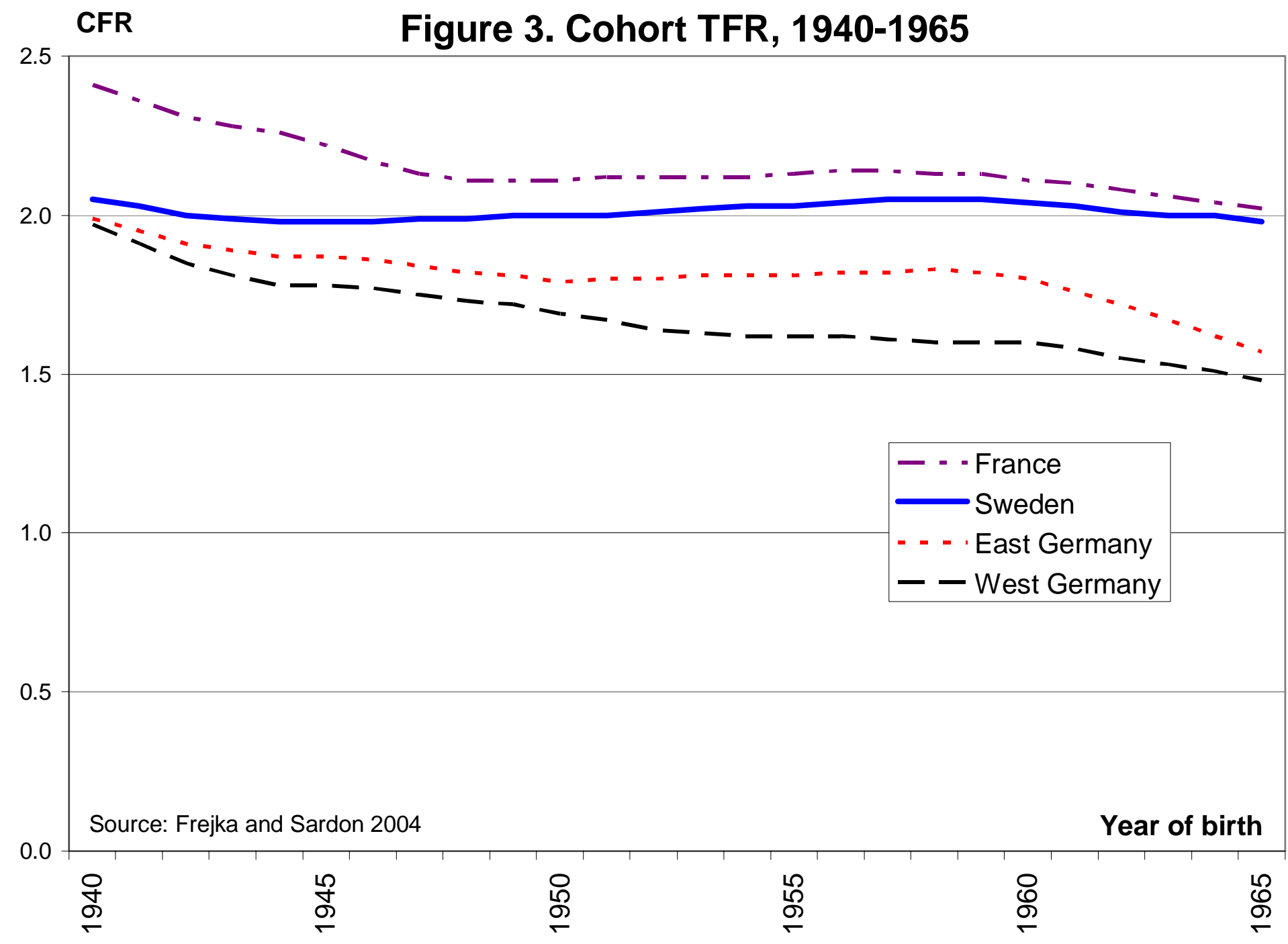




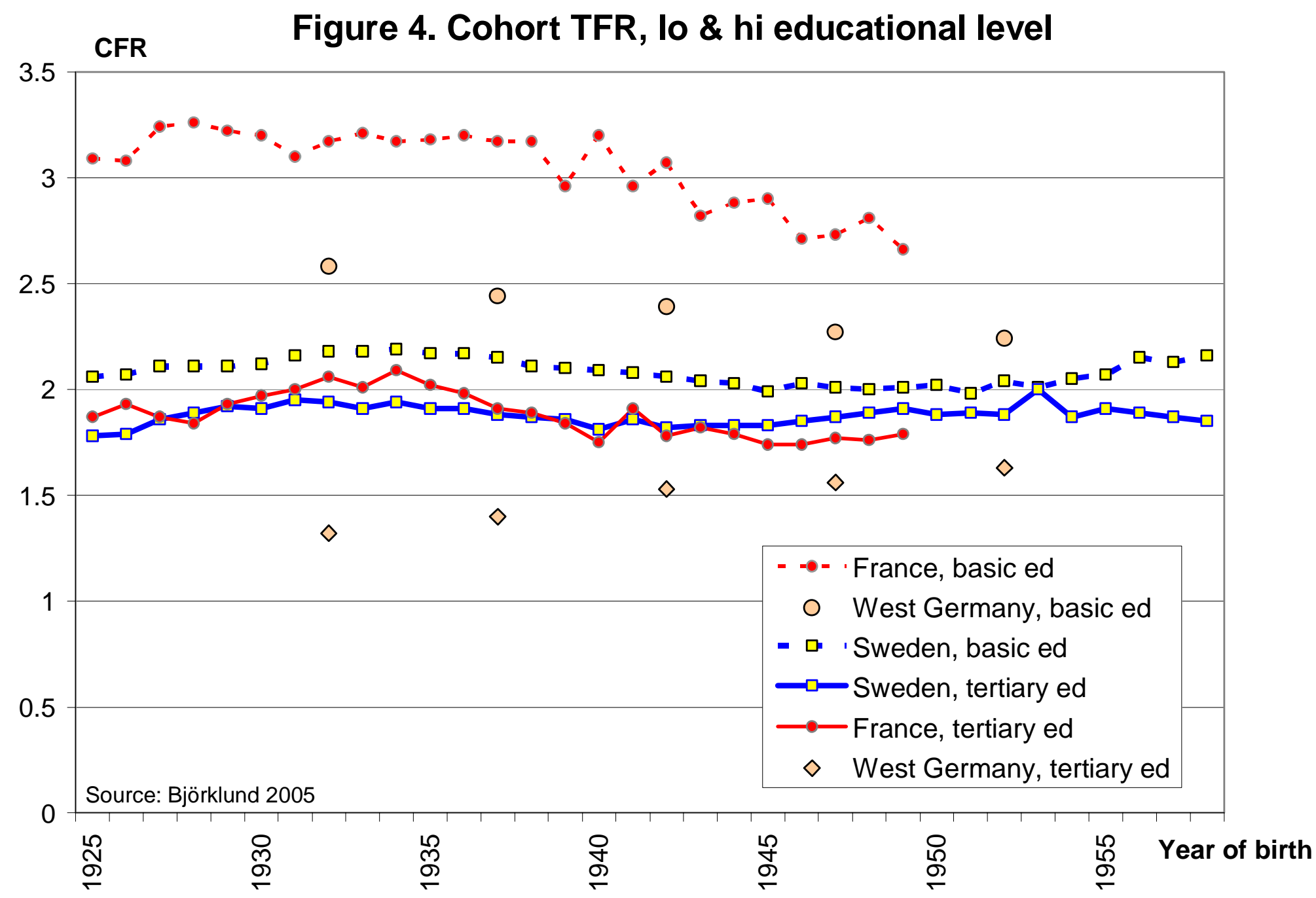

